\title{
Developing a test battery for diagnosis of childhood apraxia of speech in Arabic speakers
}

\author{
Dalia Abdou', Omayma Afsah ${ }^{2}$, Hemmat Baz ${ }^{2}$ and Tamer Abou-Elsaad ${ }^{2}$
}

\begin{abstract}
Background: Childhood apraxia of speech (CAS) is a speech sound disorder in which the precision and consistency of movements underlying speech are impaired in absence of neuromuscular deficits. It is important to differentiate between language disorders and CAS to avoid misdiagnosis. The objective of this study was to develop a test battery for CAS in order to identify its possible presence in Arabic-speaking children, thus allowing the planning of appropriate therapy programs. The constructed test battery for CAS was administered to 70 monolingual Arabicspeaking Egyptian children including 10 children with suspected CAS, 20 children with phonological disorders, and 40 typically developing children. Participants' responses were statistically analyzed to assess the validity and reliability, and to evaluate sensitivity and specificity of the test battery.

Results: Statistically significant differences were found between the three groups as regard all subtotal and total scores of CAS test battery with good validity and reliability of the test.

Conclusions: The constructed test battery for diagnosis of CAS is a reliable, valid, and sensitive tool that can be used to detect the presence of CAS in Arabic-speaking children and differentiate between it and phonological disorders.
\end{abstract}

Keywords: Childhood apraxia of speech, Speech sound disorders, Arabic consonants, Test battery

\section{Background}

Childhood apraxia of speech (CAS) is a neurological childhood (pediatric) speech sound disorder in which the precision and consistency of movements underlying speech are impaired in the absence of neuromuscular deficits (e.g., abnormal reflexes and abnormal tone). CAS may occur as a result of a known neurological impairment, in association with complex neuro-behavioral disorders of known or unknown origin, or as an idiopathic neurogenic speech sound disorder. The core impairment in planning and/or programming spatiotemporal parameters of movement sequences results in errors in speech sound production and prosody [1].

\footnotetext{
* Correspondence: omafsah@yahoo.com

${ }^{2}$ Phoniatric Unit, ORL Department, Faculty of Medicine, Mansoura University, Mansoura 35516, Egypt

Full list of author information is available at the end of the article
}

The diagnostic criteria used to identify CAS have been at the center of controversy for decades. Forrest [2] stated that the most common speech behaviors proposed to characterize CAS were inconsistent productions, difficulty with oral motor skills, difficulty with imitation of sounds, poor sound sequencing, increasing difficulty with increased utterance length, struggle, and groping [3]. Both receptive and expressive language deficits were frequently reported in CAS, with receptive skills often being superior to expressive skills [4]. Academic difficulties including reading (decoding and comprehension) and spelling difficulties were also noted. The complex of behavioral features associated with CAS leads to severely reduced speech intelligibility even to family members [5].

It is important to differentiate between language disorders and CAS to avoid misdiagnosis. A differential diagnosis of CAS is often not possible for children under the age of 2 years. Even when children are between $2-3$ years, a
Springer Open (c) The Author(s). 2020 Open Access This article is licensed under a Creative Commons Attribution 4.0 International License, which permits use, sharing, adaptation, distribution and reproduction in any medium or format, as long as you give appropriate credit to the original author(s) and the source, provide a link to the Creative Commons licence, and indicate if changes were made. The images or other third party material in this article are included in the article's Creative Commons licence, unless indicated otherwise in a credit line to the material. If material is not included in the article's Creative Commons licence and your intended use is not permitted by statutory regulation or exceeds the permitted use, you will need to obtain permission directly from the copyright holder. To view a copy of this licence, visit http://creativecommons.org/licenses/by/4.0/. 
clear diagnosis cannot always be done because, at this age, children may still be unable to focus on, or cooperate with, diagnostic testing [6]. Davis and Velleman [7] stated that the child's speech inventory should be analyzed for limited consonant and vowel inventory, flat or monotone vocal quality, and/or the lack of consistent speech patterns. Further assessment of apraxia can include articulation and phonological performance on standardized tests. Non-speech motor functions assess the child's oral structure/function and movements. A language assessment should also be completed to assess the child's level of comprehension and expression, in addition to their level of intelligibility of speech in conversation.

Many tests were designed for diagnosis of CAS in English-speaking children such as Kaufman Speech Praxis Test for Children (KSPT) [8], The Apraxia Profile [9], Quick Assessment for Apraxia of Speech [10], and Screening Test for Developmental Apraxia of SpeechSecond Edition (STDAS-2) [11].

To the best of the authors' knowledge, there is no published test battery to diagnose childhood apraxia in Arabic-speaking children.

The aim of this work was to develop an Arabic screening test for CAS in order to identify its possible presence in Arabic-speaking children, thus allowing the planning of appropriate therapy programs for these children.

\section{Methods}

\section{Subjects}

This cross-sectional descriptive study was applied on 70 monolingual Arabic-speaking Egyptian children in the age range 4-16 years who were divided into three groups. Group I consisted of 10 children with suspected CAS based on analysis of speech output obtained through spontaneous speech sample and articulation test, and children in this group were selected as they displayed some or all of the characteristics suggested by Davis et al. [12] which are markedly reduced speech intelligibility, limited phonemic repertoire, predominant use of simple syllable shapes, high incidence of vowel errors, increased errors on longer units of speech output, inconsistent articulation errors, frequent omission errors, and prosodic abnormalities. Group II consisted of 20 children with phonological disorders, who showed persistent phonological processes (whether developmental or non-developmental) but did not show signs suggestive of CAS based on clinical judgment. Group III consisted of 40 typically developing children who displayed age-appropriate speech and language skills.

Only children with an IQ $\geq 90$, with mean length of utterance of at least two words, were included in the study. Children with other developmental disorders, hearing or visual impairment, evidence of dysarthria, or history of previous language or speech therapy were excluded from the study.

Children in groups I and II were collected from children attending the Phoniatric outpatient clinic. Children in group III were collected from kindergartens and schools or from patients' relatives who agreed to participate in this study.

\section{Methods}

The Arabic test battery for childhood apraxia of speech passed through the following stages, namely, design stage, pilot study, test application stage, and data analysis stage.

\section{Design stage}

The Arabic test battery for CAS consisted of 4 test items: receptive-expressive discrepancy, consistency of speech productions, assessment of speech and nonspeech motor tasks of the articulators, and assessment of prosody.

Both receptive-expressive discrepancy and consistency of speech productions were assessed through the use of preschool language scale-4 "Arabic Version" [13] and Mansoura Arabic Articulation Test (MAAT) [14] respectively. Psychometric evaluation using Stanford Banet Intelligence Scale " 4 th Arabic Version" [15] was done for determination of IQ. Only children with an IQ of 90 and above were participating in the study.

A specially designed test battery for diagnosing CAS was constructed taking in consideration social, cultural, and language appropriateness to Arabic Egyptian culture and society for each proposed item in the test. The test was evaluated by three independent, experienced phoniatricians twice, one before the presentation of the test to the pilot study group and another evaluation after modification as suggested by the pilot study group. The final form of the test after the expert's opinion was presented to the study group. The following is a description of the test items (see Additional file 1):

\section{(1) Receptive-expressive discrepancy (RED)}

After determination of receptive language age ( $\mathrm{R}$ age) and expressive language age ( $\mathrm{E}$ age) by using the preschool language scale-4 "Arabic Version "[13], RED was calculated by subtracting receptive age from expressive age (E age-R age). Based on calculation of cutoff scores between group II and group III, each child's score on RED was interpreted as either 0\% if RED was high (the discrepancy is above $6 \mathrm{~m}$ ) or 100\% if RED was in normal range (the discrepancy is $0-6 \mathrm{~m}$ ).

(2) Consistency of speech productions 
Twenty five words of Mansoura Arabic Articulation Test (MAAT) [14] were chosen for testing consistency of speech production. These were the words presenting the sounds in word-initial position. The child was asked to name the pictures 3 times with 10 min interval between each, or separated by another activity. A score of $0 \%, 50 \%$, or $100 \%$ was given based on the following criteria:

$0 \%$ = inconsistent: if $\geq 40 \%$ of the words were inconsistent ( $\geq 10$ words).

$50 \%=$ borderline: if $10-<40 \%$ of the words were inconsistent.

$100 \%=$ consistent: if $<10 \%$ of the words were inconsistent ( $<3$ words).

(3) Assessment of speech and non-speech motor tasks of the articulators

Non-speech motor tasks were assessed through asking the child to obey some orders (6 single and 2 sequenced orders) on command and imitation. A score of $0-$ II was given based on the following criteria: $0=$ if the child failed to obey order on both command and imitation, I $=$ if the child failed to obey order on command but could obey it on imitation, and II = if the child obeyed order on command. Then, a total score was calculated as percentage (total score $=. .-. \times 10016)$.

For assessment of speech motor tasks, the child was asked to perform each of twenty four motor speech tasks twice, once immediately then after $2 \mathrm{~s}$ delay. The tasks included six isolated sounds (3 vowels and 3 consonants), three CV syllables, four CVC syllables, two clusters (CVCC), two disyllabic words, two trisyllabic words, two phrases, two sentences, and counting (automatic). For immediate imitation, a score of 0-II was given based on the child's performance as follows: $0=$ if the child could not perform the task, I = if the child produced the task immediately but with cueing, and II = if the child produced the task immediately without cueing. Cueing means helping the child to perform the task by slowing the movement with visual and $\backslash$ or tactile cue. Delayed imitation was given a score of $0-\mathrm{II}$ as follows: $0=$ if the child could not perform the task and II = if the child could perform the task.

Accordingly, each task was given a subtotal score of $0-I V$ by summation of the scores of both immediate and delayed imitation. Then, a total score was calculated as percentage (total score $=.---\times 100 / 96)$.

Diadokokinesis was tested by asking the child to repeat $|\mathrm{pa}|,|\mathrm{ta}|,|\mathrm{ka}|$, and |pa ta ka| each as fast and as long as he/she could for $6 \mathrm{~s}$ (using timer). The task was audiorecorded and scored according to both frequency and accuracy. Frequency refers to the number of repetitions the child could execute in $6 \mathrm{~s}$. The reference values, as calculated from group III children, were 15-20 repetitions for $|\mathrm{pa}|$ or $|\mathrm{ta}|$ or $|\mathrm{ka}|$ and 6-12 repetitions for $\mid \mathrm{pa}$ ta ka|. Accordingly, a child was given a score of I if it is in the normal range and 0 if below the normal range. Accuracy refers to the ability of the child to produce the sequence $\mid \mathrm{pa}$ ta ka| correctly. Correct sequence scored I, and incorrect sequence scored 0 . Then, a total score was calculated as percentage (total score $=.--.-\times 1005)$.

\section{(4) Assessment of prosody}

The child was shown five pictures and asked to comment on each picture in appropriate prosody. Two practice trials were given first for illustration. A score of 0 -III was given as follows: $0=$ if the child produced incorrect prosody even with prompt (imitation), I = if the child produced borderline prosody but with prompt, II = if the child produced correct prosody but with prompt, and III = if the child produced correct prosody spontaneously without prompt. Then, a total score was calculated as percentage (total score $=-.--\times 100 / 15)$.

The total score of CAS test battery was calculated by summation of subtotal scores in percentage (\%) then divided by 6 . The rationale of converting scores into percentages was to adjust the statistical weight of the individual items as was statistically recommended.

\section{Pilot study and test application stages}

The Arabic test battery for childhood apraxia of speech (CAS) was initially applied on 15 normal children to ensure understanding of test items. In testing consistency of speech production, the word /jas.mi:n/ which was initially chosen as representative of the sound $/ \mathrm{j} /$ was found to be difficult to identify by most children, so the picture of the word /taj.ja:.ra./ (pilot) was used instead. The test was then applied to the three study groups.

\section{Statistical analysis}

The results were collected, tabulated, and analyzed using SPSS statistical package Version 15. Qualitative data were presented as numbers and percentages. Comparison between groups was done by chi-square test. Spearman's correlation coefficient was used to test correlation between variables. $P<0.05$ was considered to be statistically significant. Spearman's correlation coefficient was used for estimating test reliability. The reliability was scaled as follows: < $0-0.25$ weak reliability, $0.25-0.75$ moderate reliability, $0.75-1$ strong reliability, and 1 optimum. Receiver operating characteristic (ROC) curve with the area under the curve (AUC) and their statistical significance was used as the indicator for total score. Identification of the cutoff value for diagnosis was 
Table 1 Demographic data of the three studied groups $(n=70)$

\begin{tabular}{llllll}
\hline & $G I$ & $G \|$ & $G$ III & & $P$ \\
$(N=10)$ & $(N=20)$ & $(N=40)$ & & \\
\hline $\begin{array}{l}\text { Age in years } \\
\text { (mean } \pm \text { SD })\end{array}$ & $7.79 \pm 3.92$ & $4.85 \pm .68$ & $6.19 \pm 1.04$ & $F=10.551$ & 0.292 \\
Gender & & & & & \\
$\quad$ Male & $7(70.0 \%)$ & $16(80.0 \%)$ & $24(60.0 \%)$ & & \\
Female & $3(30.0 \%)$ & $4(20.0 \%)$ & $16(40.0 \%)$ & $X=2.461$ & 0.290 \\
\hline
\end{tabular}

applied for statistically significant AUC where the value that maximized both sensitivity and specificity of the CAS test was chosen.

\section{Results}

The results were arranged into:

1. Descriptive data.

2. Reliability and validity of the test battery.

3. Sensitivity and specificity of the test battery.

\section{Descriptive data}

This study was conducted on a sample of 70 children divided into 3 groups: Group I (CAS group) was composed of 10 children including 7 males and 3 females in the age range $4-16$ years (mean $7.79 \pm 3.92$ ). Group II (phonological disorders group) was composed of 20 children including 16 males and 4 females in the age range $4-8$ years (mean $4.85 \pm .68$ ). Group III (normal group) was composed of 40 children including 24 males and 16 females in the age range $4-8$ years (mean $6.19 \pm 1.04$ ). The 3 groups were matched for age and sex (P-value $>0.05)$ (Table 1).

\section{Reliability and validity of the test battery}

Reliability was tested by test-retest and internal consistency reliability. In test-retest reliability, group III children were required to respond to the final form of the CAS test battery twice with 10 days interval. The results indicated excellent reliability of the test (Table 2).

Table 2 Test-retest reliability of individual items of CAS test battery

\begin{tabular}{lll}
\hline Test item & $\boldsymbol{r}$ & $\boldsymbol{P}$ \\
\hline Receptive expressive discrepancy & 0.989 & $<0.001^{* *}$ \\
Consistency of speech production & 1.000 & $<0.001^{* *}$ \\
Non-speech motor task & 1.000 & $<0.001^{* *}$ \\
Speech motor task & 1.000 & $<0.001^{* *}$ \\
Diadochokinesis & .990 & $<0.001^{* *}$ \\
Prosodic assessment & 1.000 & $<0.001^{* *}$ \\
Total score & 0.974 & $<0.001^{* *}$ \\
\hline P & &
\end{tabular}

$P$ chi-square test

${ }^{* *} p<0.001$ (highly significant)
Table 3 Internal consistency reliability of CAS test battery

\begin{tabular}{lll}
\hline Group & Items & Cronbach's Alpha \\
\hline $\begin{array}{l}\text { Apraxia } \\
\text { Group I }(N=10)\end{array}$ & 6 & $0.805^{* *}$ \\
$\begin{array}{l}\text { Phonological disorders } \\
\text { Group II }(N=20)\end{array}$ & 6 & $0.799^{*}$ \\
$\begin{array}{l}\text { Normal } \\
\text { Group III }(N=40)\end{array}$ & 6 & $0.836^{* *}$ \\
\hline
\end{tabular}

*Acceptable when $0.7 \leq a<0.8$

**Good when $0.8 \leq a<0.9$

The internal consistency reliability was analyzed using reliability coefficient alpha (Cronbach's alpha) test. Values of alpha are considered excellent when $\alpha \geq 0.9$, good when $0.8 \leq \alpha<0.9$, and acceptable when $0.7 \leq \alpha<$ 0.8 . Alpha value was good for groups I and III and acceptable for group II (Table 3).

Validity of CAS test battery was measured by content validity, internal consistency validity, and contrasted group validity. The CAS test battery proved to have excellent content validity. Internal consistency validity is a measure of test homogeneity by correlating each section subtotal with the total score. The CAS test battery proved to have good internal consistency as there were significant positive correlations between each subtotal score and the total score (Table 4).

Regarding contrasted group validity, statistically significant difference was found between group I, group II, and group III as regard all subtotal and total scores of CAS test battery $(P<0.001)$. Group I (apraxia group) recorded the lowest scores while group III (normal group) recorded the highest scores (Table 5).

\section{Sensitivity and specificity of the test battery}

Using the ROC curve and AUC for identification of cutoff values, statistically highly significant values were obtained when differentiating between groups I versus II and between groups I versus III as indicated in Tables 6 and 7 respectively.

Table 4 Correlation between subtotal and total scores of CAS test battery

\begin{tabular}{lll}
\hline Subtotal score & \multicolumn{2}{l}{ Total score } \\
\cline { 2 - 3 } & $r$ & $P$ \\
\hline Receptive expressive discrepancy & 0.86 & $<0.001^{* *}$ \\
Consistency of speech production & 0.89 & $<0.001^{* *}$ \\
Non-speech motor task & 0.74 & $<0.001^{* *}$ \\
Speech motor task & 0.87 & $<0.001^{* *}$ \\
Diadochokinesis & 0.94 & $<0.001^{* *}$ \\
Prosodic assessment & 0.92 & $<0.001^{* *}$ \\
\hline$r$ Pearson's correlation & & \\
${ }^{* *} p<0.01$ & & \\
${ }^{* *} p<0.001$ (highly significant) & &
\end{tabular}


Table 5 Comparison between the three groups in their performance on CAS test battery

\begin{tabular}{|c|c|c|c|c|}
\hline Items & $\begin{array}{l}\mathrm{Gl}(N=10) \\
(\text { mean } \pm \mathrm{SD})\end{array}$ & $\begin{array}{l}\text { Gll }(N=20) \\
(\text { mean } \pm S D)\end{array}$ & $\begin{array}{l}\text { GIII }(N=40) \\
(\text { mean } \pm S D)\end{array}$ & $\begin{array}{l}\text { Test of significance } \\
p \text { value }\end{array}$ \\
\hline Receptive expressive discrepancy & $0 \pm 0$ & $55.0 \pm 51.04$ & $100 \pm 0$ & $\begin{array}{l}2=44.3 x \\
<0.001^{* *}\end{array}$ \\
\hline Non-speech motor task & $81.25 \pm 13.8$ & $97.8 \pm 4.2$ & $99.4 \pm 1.89$ & $\begin{array}{l}F=41.06 \\
<0.001^{* *}\end{array}$ \\
\hline Speech motor task & $52.5 \pm 17.4$ & $91.7 \pm 8.8$ & $99.7 \pm 0.63$ & $\begin{array}{l}F=142.09 \\
<0.001^{* *}\end{array}$ \\
\hline Diadochokinesis & $6.00 \pm 9.6$ & $71.00 \pm 15.2$ & $98.00 \pm 7.5$ & $\begin{array}{l}x^{2}=55.9 \\
<0.001^{* *}\end{array}$ \\
\hline Consistency of speech production & $25 \pm 26.3$ & $90.00 \pm 20.5$ & $98.7 \pm 7.9$ & $\begin{array}{l}x 2=47.5 \\
<0.001^{* *}\end{array}$ \\
\hline Prosodic assessment & $31.3 \pm 19.8$ & $75.00 \pm 15.7$ & $100 \pm 0$ & $\begin{array}{l}F=160.3 \\
<0.001^{* *}\end{array}$ \\
\hline Total score & $32.6 \pm 8.7$ & $80.1 \pm 11.14$ & $99.3 \pm 1.9$ & $\begin{array}{l}F=376.5 \\
<0.001^{* *}\end{array}$ \\
\hline
\end{tabular}

Post-hoc test

${ }^{* *} p<0.001$ (highly significant)

non-parametric variables $\mathrm{K}-\mathrm{W}$ test

Accordingly, a child with score above $91.8 \%$ will be considered in the normal range. A child with score ranging between $60 \%$ and $91.8 \%$ will be considered in the phonological disorders range while a child with score less than $60 \%$ will be considered in the apraxic range (Table 8).

\section{Discussion}

This study was conducted on a sample of 70 children in the age range 4-16 years. Children above 4 years were selected because, as stated by ASHA [1], some primary characteristics of CAS (e.g., word inconsistency and a predominant error pattern) exist in the emerging speech of typically developing children under the age of 4 years. Also, there may be lack of a sufficient speech sample size for making a more definitive diagnosis below this age. Only children with average mentality were included because mental sub normality might affect children's performance on the different test items.

The Arabic Test battery for CAS consisted of 4 items including receptive-expressive language discrepancy, consistency of speech productions, assessment of speech and non-speech motor tasks of the articulators, and assessment of prosody. These items were selected depending on the main published symptoms of CAS and also based on reviewing tests for assessment of CAS in
English-speaking children such as Screening Test for Developmental Apraxia of Speech-Second Edition (STDAS-2) [11], Apraxia Profile test [9], and Nuffield Centre Dyspraxia Program-3rd Edition (NDP3) [16].

In the present study, receptive-expressive language discrepancy was evident in the apraxic group of children. This finding extends the findings of previous study [17] which demonstrated that children suspected to have CAS which typically also have significant language deficits. A research challenge was to determine how such constraints are associated with the praxis deficit in planning and programming that defines CAS. One possibility is that language impairment is a consequence of having any type of disorder affecting neurological development [18]. Another possibility is that all expressive language deficits in children with CAS are due to their speech involvements [19].

Inconsistent articulation errors on repeated speech productions of the same words or utterance are considered as one of the key features of CAS. When producing the same utterance in different instances, a person with CAS may have difficulty using and maintaining the same articulation that was previously used for that utterance [20]. Previous research on preschool-aged children shows that phonemic inconsistency of speech sounds across multiple opportunities within and across word

Table 6 Cutoff points by percentage for differentiation between group I and group II

\begin{tabular}{llllll}
\hline & Cutoff point (\%) & Area under the curve & Sensitivity & Specificity & $P$ value \\
\hline Total CAS test score & 60.00 & 1.00 & 1.00 & 0.95 & $<0.001^{* *}$ \\
\hline$p^{* *}<0.01$ & & & &
\end{tabular}

$p^{* *}<0.001$ (highly significant) 
Table 7 Cutoff points by percentage for differentiation between group I and group III

\begin{tabular}{llllll}
\hline & Cutoff point (\%) & Area under the curve & Sensitivity & Specificity & $P$ value \\
\hline Total CAS test score & 91.8 & 1.00 & 1.00 & 0.98 & $<0.001^{* *}$ \\
\hline
\end{tabular}

**statistically highly significant at $p \leq 0.001$

position differentiates children with suspected CAS and phonological disorder [3, 21].The present study supports that view as children in the apraxic group showed statistically significant impairment in their performance on the consistency subtest when compared with other groups.

Motor non-speech examination is critical for differentiating CAS from childhood dysarthria and other speech sound disorders and for identifying both oral apraxia and apraxia of speech either of which may occur in the absence of the other. Differential performance on the pairs of tasks and across tasks of varying complexity may indicate motoric difficulty with speech [22]. In the Arabic test battery for CAS, the child was asked to perform some oral non-speech movements both on command and imitation. No statistically significant difference was found between the 3 groups in their scoring on this subtest which indicated that there was no associated oral apraxia with CAS in the study sample.

The speech motor items were graded in complexity from isolated sounds to sentences. Cues (e.g., slowed rate, visual, or tactile cue) were provided to better judge the speech production and to determine how much cueing was necessary to facilitate performance. Statistically, significant difference was found in performance on speech motor tasks between the apraxic and the two other groups, being the lowest in the apraxic group. Caruso [23] and Forrest [2] stated that children with CAS always have delayed speech motor activity that affects programming more than those who suffer from phonological disorders.

Diadokokinesis (DDK) was assessed by detection of the rate and the accuracy of the child's repetitions of C$\mathrm{V}$ syllables. The score of the apraxic group was the lowest among the three groups which agreed with the previous studies [4, 24, 25]. All of these studies indicated that children with CAS suffer from inaccuracies, inconsistency, and miss-ordering in DDK production more than phonological disorders.

Inappropriate prosody, especially in the realization of lexical or phrasal stress (emphasis added), is considered as one of core features of CAS [1].The speech motor

Table 8 Total scores of CAS test battery

\begin{tabular}{ll}
\hline Apraxia & $<60 \%$ \\
Phonological disorder & $60-91.8 \%$ \\
Normal & $>91.8 \%$ \\
\hline
\end{tabular}

impairment of CAS appears to interfere with the development of the fine rapid control of articulatory muscles that are required for expression of subtle lexical stress contrasts across syllables [26, 27]. Statistically, significant differences were found between the scores of the studied groups on the prosodic assessment subtest, being the lowest in the apraxic group.

Results indicated that both reliability and validity of CAS test battery were good to excellent. Also, the percentage of sensitivity and specificity was $100 \%$ which proved its value in differentiating between normal children and those with CAS or phonological disorders.

\section{Conclusion}

The designed Arabic test battery for diagnosis of childhood apraxia of speech is a valid and reliable tool to detect the presence of CAS in Arabic-speaking children and differentiate between it and phonological disorders.

\section{Supplementary information}

Supplementary information accompanies this paper at https://doi.org/10. 1186/s43163-020-00021-5.

Additional file 1. Arabic Test battery for diagnosis of Childhood Apraxia of Speech in Arabic speakers

\section{Abbreviations}

CAS: Childhood apraxia of speech; RED: Receptive-expressive discrepancy; CV: Consonant Vowel; CVC: Consonant Vowel Consonant; CVCC: Consonant Vowel Consonant Consonant; ASHA: American Speech-Language-Hearing Association; DDK: Diadokokinesis

\section{Acknowledgements}

The authors wish to thank all the children and parents who participated in this research.

\section{Authors' contributions}

DA shared in designing the research, conducted the clinical work, contributed to data analysis, and writing the paper. OA shared in designing the research, contributed to data analysis, writing and reviewing the paper, and submit the paper for publication. HB shared in designing the research, contributed to data analysis, and reviewing the paper. TA shared in designing the research, contributed to data analysis, and reviewing the paper. All authors read and approved the final manuscript.

\section{Funding}

This research did not receive any specific grant from funding agencies in the public, commercial, or not-for-profit sectors.

Availability of data and materials

All data generated or analyzed during this study are included in this published article.

Ethics approval and consent to participate

Parents of the children have given their written informed consent to participate in the study. The study protocol has been approved by the IRB 
committee of Mansoura Faculty of Medicine, Mansoura University, Egypt (M.S./119).

\section{Consent for publication}

Not applicable.

\section{Competing interests}

The authors declare that they have no competing interests.

\section{Author details}

${ }^{1}$ Phoniatric Unit, ORL Department, Mansoura General Hospital, Mansoura, Egypt. ${ }^{2}$ Phoniatric Unit, ORL Department, Faculty of Medicine, Mansoura University, Mansoura 35516, Egypt

Received: 11 March 2020 Accepted: 7 July 2020

Published online: 21 September 2020

\section{References}

1. American Speech-Language-Hearing Association (ASHA). Childhood apraxia of speech 2007: [technical report]. Available from www.asha.org/ policy, 2007.

2. Forrest K (2003) Diagnostic criteria of developmental apraxia of speech used by clinical speech-language pathologists. Am J Speech Lang Pathol. 12:376380

3. Murray E, McCabe P, Heard R, Ballard KJ (2015) Differential diagnosis of children with suspected childhood apraxia of speech. J Speech Lang Hearing Res 58(1):43-60

4. Lewis BA, Freebairn LA, Hansen AJ, lyengar SK, Taylor HG (2004) School-age follow-up ofchildren with childhood apraxia of speech. Lang Speech Hear Serv Sch 35:122-140

5. McNeil MR (2009) Clinical management of sensorimotor speech disorders (2nd edition). Thieme Medical Publishers, Inc, New York

6. Corot K (2002) Diagnosis of AOS: definition and criteria. Semin Speech Lang J 23(4):267-280

7. Davis SL, Velleman SL (2000) Differential diagnosis and treatment of developmental apraxia of speech in infants and toddlers. Infants-Toddlers Intervention 10:177-192

8. Kaufman N. Kaufman Speech Praxis Test for Children (KSPT): Detroit, MI, Wayne State University Press (1995) New York.

9. Lori A (1997) Apraxia profile: a descriptive assessment tool for children. The Psychological Corporation, San Antonio

10. Tanner D, Culbertson W (1999) Quick assessment for apraxia of speech, Academic communication associates, Oceanside, CA

11. Robert W (2000) Screening test for developmental apraxia of speech: 2nd edition. Pro-Ed, Austin

12. Davis BL, Jakielski KJ, Marquardt TP (1998) Developmental apraxia of speech: determiners of differential diagnosis. Clin Ling Phonetics. 12(1):25-45

13. Abo-Hasseba A. Standardization, translation and modification of the preschool language scale-4. Unpublished M.D Thesis of Phoniatrics presented by A. Abu-Hasseba, Faculty of medicine, Ain Shams university (2011).

14. Abou-Elsaad T, Baz H, El-Banna M (2009) Developing an articulation test for Arabic-speaking school age children. Folia phoniatrica et Logopaedica 61: 275-282

15. Melika L (1998) Stanford Binet intelligence scale (4th Arabic version): second edition. Victor Kirles Press, Cairo

16. Miracle, Nuffield Centre Dyspraxia Programme $3^{\text {rd }}$ Edition (NDP3): Nuffield Speech and Hearing Centre (2004) the Miracle Factory.

17. Ozanne A (2007) The speech of children with developmental apraxia of speech. In: Dodd B (ed) Differential diagnosis and treatment of children with speech disorder. Whurr, London, pp 91-109

18. Robin DA (1992) Developmental apraxia of speech, just another motor problem. Am J Speech Lang Pathol 1:19-22

19. Ekelman BL, Aram DM (1983) Syntactic findings in developmental verbal apraxia. J Commun Disord 16:237-250

20. Maassen B (2002) Issues contrasting adult acquired versus developmental apraxia of speech. Semin Speech Lang J 23:257-266

21. Iuzzini-Seigel J, Hogan T, Green J (2017) Speech inconsistency in children with childhood apraxia of speech, language impairment and speech delay: depends on the stimuli. J Speech Lang Hearing Res 2(2):47-57
22. Mccauley RJ, Strand EA (2008) A review of standardized tests of nonverbal oral and speech motor performance in children. Am J Speech Lang Pathol. 17:81-91

23. Caruso A (1999) Motor speech disorders in children: definitions, background and a theoretical framework. In: Caruso A, Strand EA (eds) Clinical management of motor speech disorders in children. Thieme, New York, NY, pp 1-27

24. Williams P, Stackhouse J (2000) Rate, accuracy, and consistency, diadochokinetic performance of young, normally developing children. Clin Ling Phonetics 14(4):267-293

25. Velleman S.L., Huffman M.J., Mervis C.B. Relations between speech and motor-speech performance in children with duplication syndrome. Paper presented at the International Child Phonology Conference, Minneapolis (2012) MN.

26. Shriberg L, Aram D, Kwiatkowski J (1997) Developmental apraxia of speech, a subtype marked by inappropriate stress. J Speech Lang Hearing Res. 20(2): 313-337

27. Skinder A, Strand EA, Mignerey M (1999) Perceptual and acoustic analysis of lexical and sentential stress in children with developmental apraxia of speech. J Med Speech Lang Pathol 7:133-144

\section{Publisher's Note}

Springer Nature remains neutral with regard to jurisdictional claims in published maps and institutional affiliations.

\section{Submit your manuscript to a SpringerOpen ${ }^{\circ}$ journal and benefit from:}

- Convenient online submission

- Rigorous peer review

- Open access: articles freely available online

- High visibility within the field

- Retaining the copyright to your article

Submit your next manuscript at $\boldsymbol{\nabla}$ springeropen.com 